\title{
Comparative Study of Endonasal Endoscopic Dacryorhinostomy with or without Intraoperative Mitomycin C
}

Nitin Kumar Jain, Siddharth Vashistha, Sandeep Kaushik

\section{ABSTRACT}

Objective: Endoscopic dacryocystorhinostomy (DCR) has known advantages over external DCR as a less invasive method without the need of any skin incision. Mitomycin C (MMC), a wound healing inhibitor, was used intraoperatively with the objective of reducing incidence of adhesion and synechiae formation as a postoperative complication leading to failure of the procedure.

Materials and methods: Endoscopic DCR was performed in 60 patients. MMC $(0.5 \mathrm{mg} / \mathrm{dl}$ for 5 minutes $)$ was applied to the ostium in 30 patients in comparison with control group.

Results: The postoperative follow-up was done at 1, 3 weeks and 3 months. The success rate of endoscopic DCR with intraoperative MMC was $90 \%$ whereas it was found to be $83.33 \%$ in control group. The statistical analysis did not show a difference between the two groups according to success rates.

Conclusion: Adjunctive use of a wound healing inhibitor may be considered to increase the success rate of endoscopic DCR. Its intraoperative use seems to be easy and safe. This study of limited series needs further extensive evaluation to establish the adjunctive use of MMC in endoscopic DCR in future.

Keywords: Mitomycin C, Endoscopic, Dacryocystorhinostomy.

How to cite this article: Jain NK, Vashistha S, Kaushik S. Comparative Study of Endonasal Endoscopic Dacryorhinostomy with or without Intraoperative Mitomycin C. Clin Rhinol An Int J 2013;6(2):77-79.

\section{Source of support: Nil}

Conflict of interest: None declared

\section{INTRODUCTION}

The endoscopic approach has several advantages; it provides a better esthetic result with no external scar. It allows a onestage procedure to also correct associated nasal pathology that may be causative. It avoids injury to the medial canthus and/or pathologic scar formation. It preserves the pumping mechanism of the orbicularis oculi muscle. ${ }^{1}$ The first report of dacryocystorhinostomy (DCR) was by Caldwellin 1893. Caldwell created a rhinostomy using an intranasal approach by removing a portion of the inferior turbinate and following the nasolacrimal duct to the lacrimal sac and described the operation via the endonasal approach. ${ }^{2}$ In 1980 McDonogh and Meiring used the modern nasal endoscopic approach and described improved results. ${ }^{3}$

The two most common causes of failure in DCR surgery are closure of the surgically created osteotomy with soft tissue obstruction at the common canaliculus. Antiproliferative agent applied at the osteotomy site may reduce the fibrosis and hence the failure rate. Mitomycin $\mathrm{C}$ (MMC) and 5-fluorouracil have been equally successful in this regard. ${ }^{4}$

In this prospective randomized study, we aim to identify role of MMC in endonasal endoscopic DCR and to correlate the efficacy of endonasal endoscopic DCR with or without MMC.

\section{MATERIALS AND METHODS}

For the present study 60 cases of chronic dacryocystitis were selected and underwent endoscopic DCR at our institution from December 2010 to August 2012. Patients presenting with epiphora and discharge from the eye due to a distal obstruction of nasolacrimal duct were included in the criteria for endoscopic DCR.

Patient included into the study were divided into 2 groups, the control group undergo endonasal DCR and the study group undergo endonasal DCR with local application of MMC.

Patients of proximal duct obstruction, revision cases and patients who did not follow-up for 3 months were excluded from our study.

\section{Operative Procedure}

- All procedures were done under local anesthesia/general anesthesia.

- Patient's head was tilted $15^{\circ}$ upwards and turned to the right of the patient, i.e. toward the surgeon.

- A $4 \mathrm{~mm}, 0$ or $30^{\circ}$ endoscope was introduced into the nasal cavity and whole of the nasal cavity was visualized.

- The mucosa of the lateral nasal wall infiltrated with $2 \mathrm{ml}$ of $2 \%$ xylocaine with 1:100,000 adrenaline just anterior to the uncinate process.

- The $1.5 \times 2 \mathrm{~cm}$ piece of mucosa anterior to the anterior attachment of middle turbinate removed off after incision with sickle knife.

- Corresponding lacrimal bone and frontal process of maxilla are removed using Kerrison bone punch starting from maxillary line.

- Medial wall of sac is incised using sickle knife and excised as much as possible using Blakesley forcep. 
- Patency is checked by saline irrigation via inferior canaliculus and flow into nasal cavity through new stoma is visualized.

- Light anterior nasal packing for hemostasis.

- Intraoperative use of MMC.

- A piece of Merocel surgical sponge soaked in $0.2 \mathrm{mg} / \mathrm{ml}$ MMC was applied over osteotomy margins for 5 minutes.

\section{Postoperative Care}

- The nasal pack was removed after 24 hours.

- All patients were given systemic oral antibiotic and analgesics for 5 days. Antibiotic eye drops were advised 6 times daily for 3 days. Nasal decongestant drops were instilled 6 drops 3 times a day for 3 days.

- All patients were followed at first week, third week, and third month postoperatively.

- Nasal endoscopy with syringing was done in each visit and looked for patency, any crusting, granulations and secretions and were removed.

- On the basis of these findings results were classified into patent, partially blocked and completely blocked nasolacrimal duct and compared with each group to evaluate the success rate.

\section{OBSERVATIONS AND RESULTS}

All the 60 patients $(100 \%)$ had epiphora as the main complaint of these, 55 patients had purulent discharge associated with epiphora (Table 1). In our study patients were divided with equal sex ratio $(1: 3.28)$ with seven males and 23 females in each group. Mean age of control group was 33.43 and that of MMC group was 33.36 (Table 2).

\begin{tabular}{lccc}
\multicolumn{3}{c}{ Table 1: Symptomatological distribution } \\
Symptoms & $\begin{array}{c}\text { Control group } \\
\text { without MMC } \\
\text { no. }\end{array}$ & $\begin{array}{c}\text { MMC } \\
\text { group } \\
\text { no. }\end{array}$ & $\begin{array}{c}\text { Total } \\
\text { no. }\end{array}$ \\
\hline $\begin{array}{l}\text { Simple epiphora without } \\
\text { discharge }\end{array}$ & 3 & 2 & 5 \\
$\begin{array}{l}\text { Epiphora associated } \\
\text { with discharge }\end{array}$ & 27 & 28 & 55 \\
\hline
\end{tabular}

\begin{tabular}{lcc}
\multicolumn{3}{c}{ Table 2: Clinical characters of cases } \\
& $\begin{array}{l}\text { Control group } \\
\text { without MMC }\end{array}$ & MMC group \\
& 30 & 30 \\
\hline Number of cases & 33.43 & 33.36 \\
Mean age & $1: 3.28$ & $1: 3.28$ \\
Sex ratio & \\
\hline
\end{tabular}

All patients underwent endoscopic DCR and as shown in Table 3, both groups had intraoperative hemorrhage in $3.33 \%$ patients but hemostasis was achieved at the end of the procedure. Two patients of the control group suffered from wound infection $(6.67 \%)$ and one patient from the MMC group had similar complaints which were successfully treated with antibiotics. Ten patients (33.3\%) of the control group and eight patients of the MMC group had postoperative excessive crusting which were removed at each follow-up. Three (10\%) patients of the control group and one $(3.33 \%)$ patient of MMC group had granulations postoperatively which were seen at regular follow-up. Four $(13.33 \%)$ patients of the control group and three $(10 \%)$ patients of the MMC group had synechiae in their nasal cavity (Table 3).

\begin{tabular}{|c|c|c|c|c|}
\hline & \multicolumn{2}{|c|}{$\begin{array}{l}\text { Control group } \\
\text { without MMC }\end{array}$} & \multicolumn{2}{|c|}{ MMC group } \\
\hline & Number & $\%$ & Number & $\%$ \\
\hline Hemorrhage (primary) & 1 & 3.33 & 1 & 3.33 \\
\hline Wound infection & 2 & 6.67 & 1 & 3.33 \\
\hline Crusting & 10 & 33.33 & 8 & 26.67 \\
\hline Synechiae & 3 & 10 & 1 & 3.33 \\
\hline Granulations & 4 & 13.33 & 3 & 10 \\
\hline
\end{tabular}

In our study, patients were followed up on 1st week, 3rd week and 3 months and at 3 rd month $83.33 \%$ of the patients in control group and $90 \%$ of those in MMC group showed complete cure with clear flow of saline into nasal cavity on sac syringing (Table 4).

\section{DISCUSSION}

In the present study success rate of $83.33 \%$ in endoscopic DCR without MMC (control group) and $90 \%$ in endoscopic DCR with intraoperative MMC group was achieved. No significant difference exists between two groups.

Zilelioglu et al (1998) found that success rate of endoscopic DCR with intraoperative MMC was $77.3 \%$ whereas without MMC was $77.8 \%$ for ostium size. Hence, there was no difference between two groups regarding ostium size and success rate. ${ }^{5}$

Roozitalab et al (2004) said that use of intraoperative MMC in DCR does not change success rate of this procedure. $^{6}$

Farahani et al (2008) conducted prospective doubleblind randomized clinical trial and showed that patients with nasolacrimal duct obstruction who underwent endoscopic DCR did not benefit from adjunctive topical application of MMC. $^{7}$

Although, clinically there were lesser complications in MMC group as compared to the control group but statistically they were not significant but the results were comparable to the above studies.

\section{CONCLUSION}

Utilizing the antifibroblastic activity of MMC in preventing scarring at osteotomy site in endoscopic DCR can go a 
Comparative Study of Endonasal Endoscopic Dacryorhinostomy with or without Intraoperative Mitomycin C

\begin{tabular}{|c|c|c|c|c|c|c|}
\hline \multicolumn{7}{|c|}{ Table 4: Results } \\
\hline \multirow{2}{*}{$\begin{array}{l}\text { Period of } \\
\text { observation }\end{array}$} & \multicolumn{3}{|c|}{ Control group without $M M C$} & \multicolumn{3}{|c|}{ MMC group } \\
\hline & Patient (\%) & $\begin{array}{c}\text { Partially blocked } \\
\text { (\%) }\end{array}$ & Blocked (\%) & Patient (\%) & $\begin{array}{c}\text { Partially blocked } \\
\text { (\%) }\end{array}$ & Blocked (\%) \\
\hline 1st week & 90 & 6.67 & 3.33 & 96.67 & 3.33 & 0 \\
\hline 3rd week & 86.67 & 6.67 & 6.67 & 93.33 & 3.33 & 3.33 \\
\hline 3rd month & 83.33 & 3.33 & 13.33 & 90 & 3.33 & 6.67 \\
\hline
\end{tabular}

long way in preventing the reblockage and maintaining the postoperative patency of passages.

Distinctly minimum success rate have been achieved in patients undergoing DCR with intraoperative MMC as compared to patients undergoing control DCR.

Adjunctive use of a wound healing inhibitor is considered to increase the success rate of endoscopic endonasal DCR. Its intraoperative use seems to be easy and safe. But the study of this limited series shows no benefit in using it and warrants further evaluation in larger numbers having survival studies in future.

\section{REFERENCES}

1. Fernades, Valentine S.; Meyers, Arlen D. Dacryocystorhinostomy [internet]. 2010 [updated: Apr 26, 2010]. Available from: http// emedicine.medscape. com/article/879096-overview.

2. Caldwell GW. Two new operations for obstruction of the nasal duct with preservation of the canaliculi, and an incidental description of a new lacrimal probe. New York Med J 1893;57:581-582.

3. McDonough M, Meiring JH. Endoscopic transnasal dacryocystorhinostomy. J Laryngol Otol 1989 Jun;103(6):585-587.

4. Fergie, Neil; Jones, Nicholas S. Dacryocystorhinostomy. In: Gleeson, Michael; editor. Scott-Brown's otorhinolaryngology head and neck surgery. 7th ed. Great Britain: Hodder Arnold; 2008. p. 1689-1695.
5. Zilelioğlu G, Uğurbaş SH, Anadolu Y, Akiner M, Aktürk T. Adjunctive use of mitomycin C on endoscopic lacrimal surgery. Br J Ophthalmol 1998 Jan;82(1):63-66.

6. Roozitalab MH, Amirahmadi M, Namazi MR. Results of the application of intraoperative mitomycin $\mathrm{C}$ in dacryocystorhinostomy. Eur J Ophthalmol 2004 Nov-Dec;14(6): 461-463.

7. Farahani F, Ramezani A. Effect of intraoperative mitomycin C application on recurrence of endoscopic dacryocystorhinostomy. Saudi Med J 2008 Sep;29(9):1354-1356.

\section{ABOUT THE AUTHORS}

\section{Nitin Kumar Jain}

Postgraduate Student, Department of Otorhinolaryngology, GSVM Medical College, Kanpur, Uttar Pradesh, India

Correspondence Address: Room No. 57, PG Boys Hostel, GSVM Medical College, Kanpur, Uttar Pradesh, India, Phone: 8853207095 e-mail: nitinjain70@gmail.com

\section{Siddharth Vashistha}

Postgraduate Student, Department of Otorhinolaryngology, GSVM Medical College, Kanpur, Uttar Pradesh, India

\section{Sandeep Kaushik}

Associate Professor and Head, Department of Otorhinolaryngology GSVM Medical College, Kanpur, Uttar Pradesh, India 